\title{
NOTES ON EUPONERA GILVA (ROGER) (HYMENOPTERA, FORMICIDAE)
}

\section{By Wm. S. Creighton and George S. Tulloch ${ }^{1}$}

In a collection of ants made by the senior author in Alabama during the months of May and June, 1929, there are many specimens of $E$. gilva (Roger). These are of interest both because of the presence of sexual forms, which have not been previously described, and also because of their bearing on the subspecies harnedi, recently described by M. R. Smith. The total number of specimens secured was about three hundred. Most of these came from one unusually large nest found at Point Clear, Baldwin County. Others were taken at Spring Hill (Mobile), and a very interesting nest containing five deälated females was discovered near Florence. It would appear that gilva is by no means as rare as was formerly supposed. Its scarcity in collections may be ascribed to the combination of a restricted type of nesting site and a southern range which has kept it out of the hands of collectors. It prefers to nest under the bark of fallen pine trees, selecting trees which are lying in such a position that the trunk is clear of the ground for at least a part of its length. The nests are made in the thin and rather spongy layer between the bark and the wood and always on the under side of the trunk. This insures an abundant supply of moisture, which is apparently indispensable to these insects. With the single exception noted above, all the colonies found were small. Many males, a single winged and somewhat callow female and much well-developed brood came from the Point Clear colony which was taken June 20 .

$E$. gilva was originally described by Roger in 1863 . Emery in 1895 corrected and amplified the description and

${ }^{1}$ Contribution from the Entomological Laboratory of the Bussey Institution, Harvard University, No. 329. 
figured the thorax. Wheeler and Gaige in 1920 redescribed the insect from specimens taken at Camden, Tennessee. Unfortunately the figure which was to accompany the description was omitted in publication. In 1929 M. R. Smith erected a new subspecies which he called harnedi. The types of this insect were found at Columbus, Mississippi. The paper containing the account of this subspecies was received while the present work was in preparation. From certain remarks made by Dr. Smith in his introduction, it was apparent that some mistake had been made in regard to the cotypes of harnedi. These were supposed to have been examined by Dr. Wheeler, but upon inquiry the single specimen from the type series present in his collection proved to be a female. Under such conditions it was manifestly impossible that any opinion of the status of the worker could have come from Dr. Wheeler. Furthermore this female of harnedi was so similar to those of the typical gilva taken by the senior author that the validity of harnedi seemed very questionable. To clear up the matter cotypes of harnedi were secured through the coöperation of Dr. Smith. The authors are glad to take this opportunity to thank him for the gift of these specimens and also for his consideration in laying aside his own description of the sexual forms, which was in course of preparation at the time when he learned of this paper.

A comparison of the cotypes of harnedi with specimens which we regard as the typical gilva has convinced us that the former must be regarded as a synonym. The two insects are identical as to the width of the head, the length of the antennal scapes and the size of the eyes. The specimens of harnedi are as robust as those of gilva and their size is well within the range shown by the latter. In coloration Dr. Smith's specimens are identical with the darker specimens taken in the Point Clear colony, the thorax being practically as dark as the head, and the appendages a rather dingy brownish yellow. This condition is apparently shown by the older individuals in the colony, since there are many specimens from the same nest in which the thorax is somewhat lighter than the head and the appendages are of a clear brownish yellow. We were unable to detect any significant difference in the sculpture of the two, although 
the pronotum and mesonotum of harnedi appeared a trifle more glabrous than that of some of the specimens of the typical gilva. The abdominal pilosity of harnedi also seemed slightly longer and more abundant, but here again it was impossible to make a satisfactory distinction because of the variability of the typical form. We are of the opinion that the minor differences shown by harnedi are those which have been used to distinguish the so-called nest variety. To establish varietal status on this basis necessitates the frequent splitting of a series from a single colony, a procedure which we consider taxonomically unsound. The authors feel sure that Dr. Smith will agree that synonymy is preferable to the use of such minute distinctions.

It may be of interest to note here that the name gilva appears to have been a misnomer. As ordinarily used gilva refers to the light yellow color more often characterized by the term flavus or flava. The name gilva, therefore, seems scarcely applicable to the ferrugineous specimens which have been found to represent this form, and one is justified in questioning that our present material is of the same color as Roger's types. That the latter were also ferrugineous is indicated by Emery's statement in his description of '95. Emery had for study two workers from the Berlin Museum. Although these do not seem to have been cotypes, they were, in all probability, compared with Roger's original specimens. Emery notes that their color is much darker than that of the European ochracea. There are two specimens of ochracea, taken by Emery, in the collection of Dr. Wheeler. The color of these is a clear, golden yellow, notably lighter than that of any specimen of gilva which we have seen. We may consequently conclude that the color of Emery's specimens of gilva, and presumably Roger's also, was the same as that of our present material.

Descriptions of the sexual forms of E. gilva and figures of all three casts are presented below:

Euponera (Trachymesopus) gilva (Roger)

Ponera gilva,

Roger, Berl. Ent. Zeitschr., Vol. 5, p. 170, (1863).

Mayr, Verh. Zool-bot. Ges. Wien, Vol. 36, p. 438, (1886) 
Dalla Torre, Cat. Hymenop., Vol. 7, p. 39, (1893).

Emery, Zool. Jahrb. Abth. Syst., Vol. 8, p. 266, pl. 8, fig. 10, (1895).

Wheeler, Ants, etc., p. 561, (1919).

Pachycondyla, (Pseudoponera) gilva, Emery, Ann. Soc. Ent. Belg., Vol. 45, p. 46, (1901).

Euponera (Trachymesopus) gilva, Emery, Genera Insect., Ponerinae, p. 86. Wheeler and Gaige, Psyche, Vol. 27, p. 69, (1920).

Euponera (Trachymesopus) gilva subsp. harnedi, Smith, Ann. Soc. Ent. Amer., Vol. 22, p. 534, (1929).

It is not necessary to repeat here the description of the worker of gilva since a very satisfactory account of this caste has already been given by WheeTer and Gaige ('20). It may be well, however, to mention in passing certain features which were not noted in their description. The greatest width of the head, which occurs approximately at the posterior third, is to the length as $3.7: 4$. The eyes consist of eight or nine poorly defined ommatidia which are partially obscured by overlying pubescence. The penultimate and antepenultimate joints of the funiculus are very slightly longer than broad and not, as has been stated, broader than long. Their true proportions are obscured in dry specimens by the erect hairs which they bear, but become apparent when the specimen is examined in a liquid mount. The ventral surface of the node of the petiole bears a rounded anterior lamella and a somewhat more flattened posterior lobe.

Female.-Length 4.7-5.2 mm.

Head relatively broader than in the worker, its greatest width approximately equal to the length, the sides less evenly convex than in the worker, much narrower in the anterior half than in the posterior, the occipital angles well-marked, the occiput straight or at most very feebly concave. Mandibles large, their external border almost straight, except at the apical third, where it is feebly 
convex. Apex of the mandible with a long, stout, sharp tooth, which is longer than any of the other teeth on the masticatory margin, the first three of these large and rather blunt, the innermost three smaller and set very close together. Clypeus with a well-marked, steeply declivious and acutely triangular median lobe, the apex of which lies between the anterior ends of the frontal lobes. Anterior border of the clypeus feebly convex with sinuate lateral terminations. Eyes oval, moderately large, their anterior border separated from the insertion of the mandible by a distance less than the thickness of the antennal scape at its apex. Ocelli of moderate size, equidistant from each other. Frontal lobes flattened, together forming a subcordiform plate which is divided by a longitudinal impression that is continuous with the frontal groove, the latter extending back to the median ocellus. Antennæ twelve-jointed, the funiculus twice as long as the scape. The scape in repose fails to reach the occipital border by a distance one and one-half times its greatest thickness. First funicular joint somewhat longer than the following two together; joints two to seven all broader than long; joint eight as broad as long; joints nine and ten slightly longer than broad; terminal joint slightly longer than the two preceding joints together.

Thorax narrow, its maximum width one-half its length. The dorsum of the thorax in profile feebly convex. Pronotum with a short and very declivious anterior face descending to the neck. Seen from above the humeral angles are much rounded, which with the strongly concave posterior border, gives the pronotum a crescentric appearance. Scutum sub-trapezoidal, one-sixth broader than long, the anterior border strongly convex. Notauli (Mayrian furrows) absent, parapsidal furrows present, extending two-thirds of the distance to the anterior margin of the scutum. Scutellum small, suboval in outline, scarcely half as wide as the greatest width of the thorax. Metanotum very narrow, arcuate in shape. Epinotum seen from above rectangular, the dorsum one-fourth wider than long. In profile the basal face is considerably shorter than the declivious, which it meets at a sharp angle. Petiole very similar to that of the worker, the anterior face steeply sloping, the anterior face virtually perpendicular, the summit 


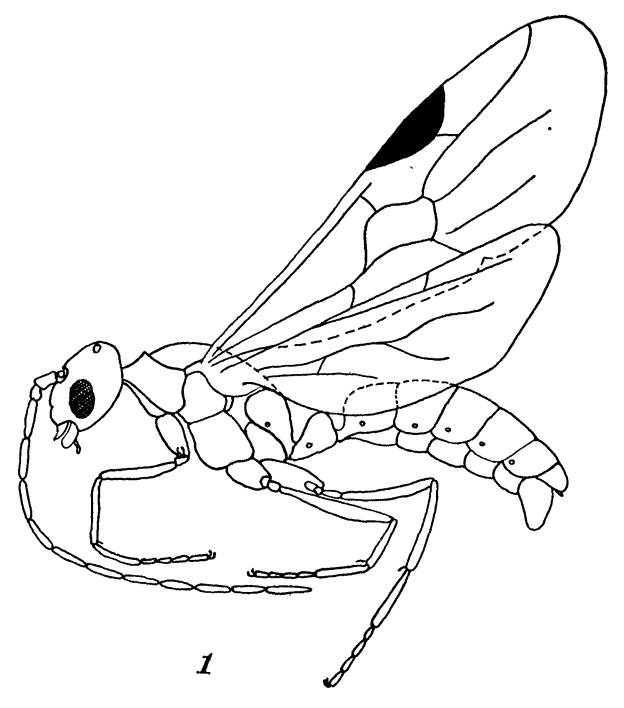


very thick and obtusely rounded. The ventral surface of the node bears posteriorly a swollen lobe and anteriorly a thin, evenly convex lamella. Seen from above the node is transverse, the apex, which is broader than the more ventral portions, is approximately twice as wide as thick. Gaster elliptical, the constriction between the first and second segments rather feeble.

Color ferrugineous, the head and mandibles somewhat darker, the thorax marked with irregular areas of yellow, particularly on the pronotum and scutum; petiole and abdomen of a somewhat clearer tint, the posterior borders of the gastric segments with broad piceous bands. Antennæ and legs brownish yellow. Cephalic punctures so closely approximated that the head appears to be covered with minute coriaceous rugulae, giving it an opaque texture which shows a dull sheen in certain lights. Thorax more shining, the punctures not so closely approximated, the epinotum somewhat more shining than the rest of the thorax. Petiole and abdomen strongly shining, the punctures about as numerous as those on the epinotum but very small. Mandibles highly glabrous, the punctures very sparse and minute. Head covered with moderately abundant, appressed pubescence, which becomes much longer and coarser on the frontal lobes. Pubescence on the thorax and petiole somewhat finer and sparser. Abdominal pubescence very abundant, longer, coarser and more erect than elsewhere. Erect hairs on the head sparse and short with the exception of one or two very long ones which are inserted at either side of the medium lobe of the clypeus. Those on the thorax longer and more abundant. Erect hairs on the gaster numerous, particularly at the edges of the posterior segments. Tarsi and funicular joints with numerous, short, stout, erect hairs. Wings grizzled, the veins and stigma yellow, the entire wing covered with numerous, fine, short, suberect hairs.

Male.-Length $3.9 \mathrm{~mm}$.

Head subtrapezoidal, much narrowed behind, its greatest width (measured through the eyes) slightly greater than its length, occiput narrow, scarcely wider than the distance 
between the lateral ocelli, sides moderately convex. Eyes large, convex, suboval in outline, their margin bounded by a narrow and shallow groove, the posterior border lies at the middle of the side of the head, the anterior border separated from the insertion of the mandible by a distance equal to the thickness of the first funicular joint. Ocelli large and prominent, the two lateral ocelli separated from each other by a distance almost twice as great as that which separates each from the median ocellus. Clypeus subtrapezoidal, the median portion somewhat elevated, the anterior edge feebly sinuate. Mandibles small, rather broad at the base which bears a curious, oval impression, but with a narrow though rounded apex, entirely without teeth, Antennæ filiform, of thirteen joints. First joint cylindrical, about one and one-half times as long as thick; second joint thinner, more rounded, about as broad as long; the remaining joints all much more slender, five times as long as thick.

Thorax seen in profile with a feebly convex dorsum, the pronotum steeply declivious throughout, the small anterior portion forming the neck not well differentiated from the rest; seen from above the pronotum is cresentric in outline and separated from the scutum by a very pronounced suture. Scutum subtrapezoidal, the anterior face evenly convex, its greatest width five-sixths of its length. Notauli (Mayrian furrows) absent, parapsidal furrows extending forward two-thirds of the distance to the anterior margin of the scutum. Scutellum small, rather convex, its dorsum triangular in outline but spreading ventrally to form a quadrate outline. Metanotum thicker and less arcuate than in the female. Epinotum seen from above tapering towards the rear, without sharp definition between the basal and declivious faces. Seen from the side the two faces appear as a continuous curve. Node of the petiole low and thick, the anterior face steeply declivious, the posterior face perpendicular, the summit thick and evenly convex, the ventral surface without lobe or lamella. Gaster very elongate, its greatest width three-eighths of its length, a feeble constriction between the first and second segments.

Color dirty blackish brown, the thorax more or less marked with dirty yellow. The posterior gastric segments 
with a narrow band of sordid yellow at the base. Occiput and frontal area piceous. Antennæ and legs dirty yellow. Punctures throughout less numerous than in the female, not sufficiently abundant on the head to produce the opaque appearance characteristic of the female and worker, the head feebly shining. Thorax, except for the epinotum, with the same punctuation as the head. Epinotum, petiole and gaster strongly shining, the punctures very fine and much less abundant. Pubescence on the occiput and front short, fine and appressed; longer, coarser and suberect on the clypeus, thorax and petiole; very long, sparse and suberect on the gaster where it grades into upright hairs at the edges of the segments. Occiput and clypeus with a few long erect hairs. Antennal joints with numerous, short, erect hairs; those of the tarsi, longer, sparser and less erect. Wings grizzled with yellow veins and stigma, the entire wing covered with numerous, short, suberect hairs. In certain lights the wings are iridescent. 

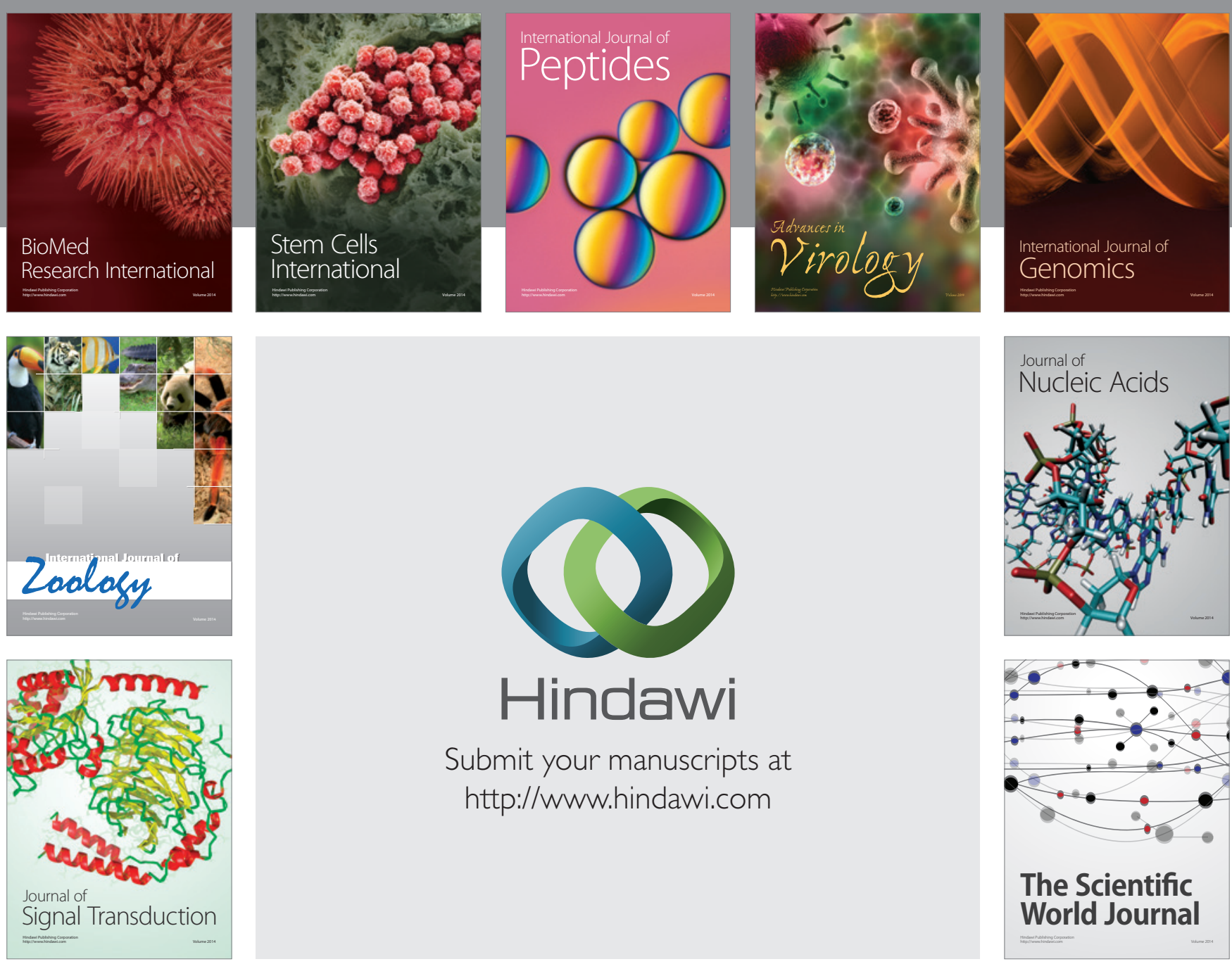

Submit your manuscripts at

http://www.hindawi.com
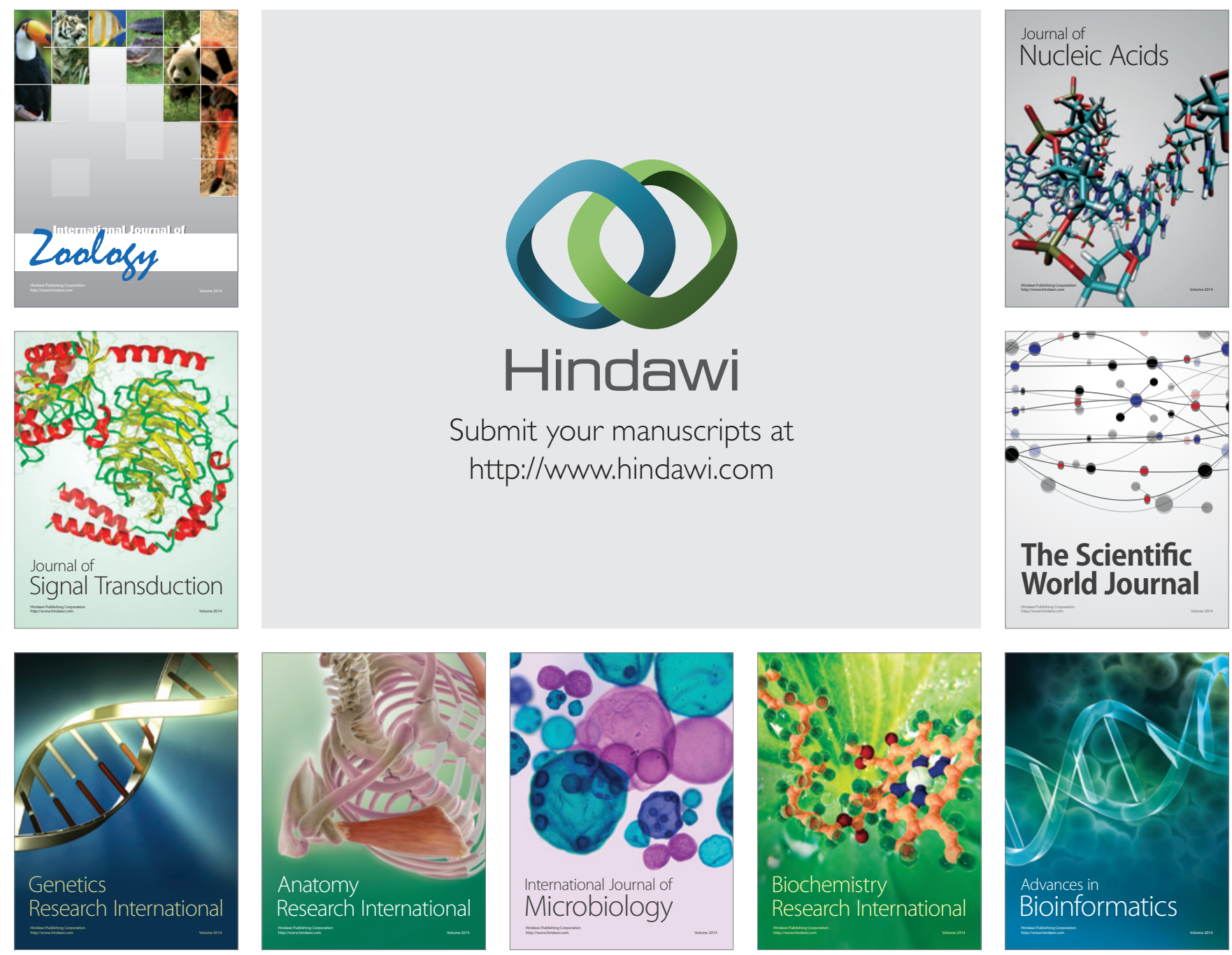

The Scientific World Journal
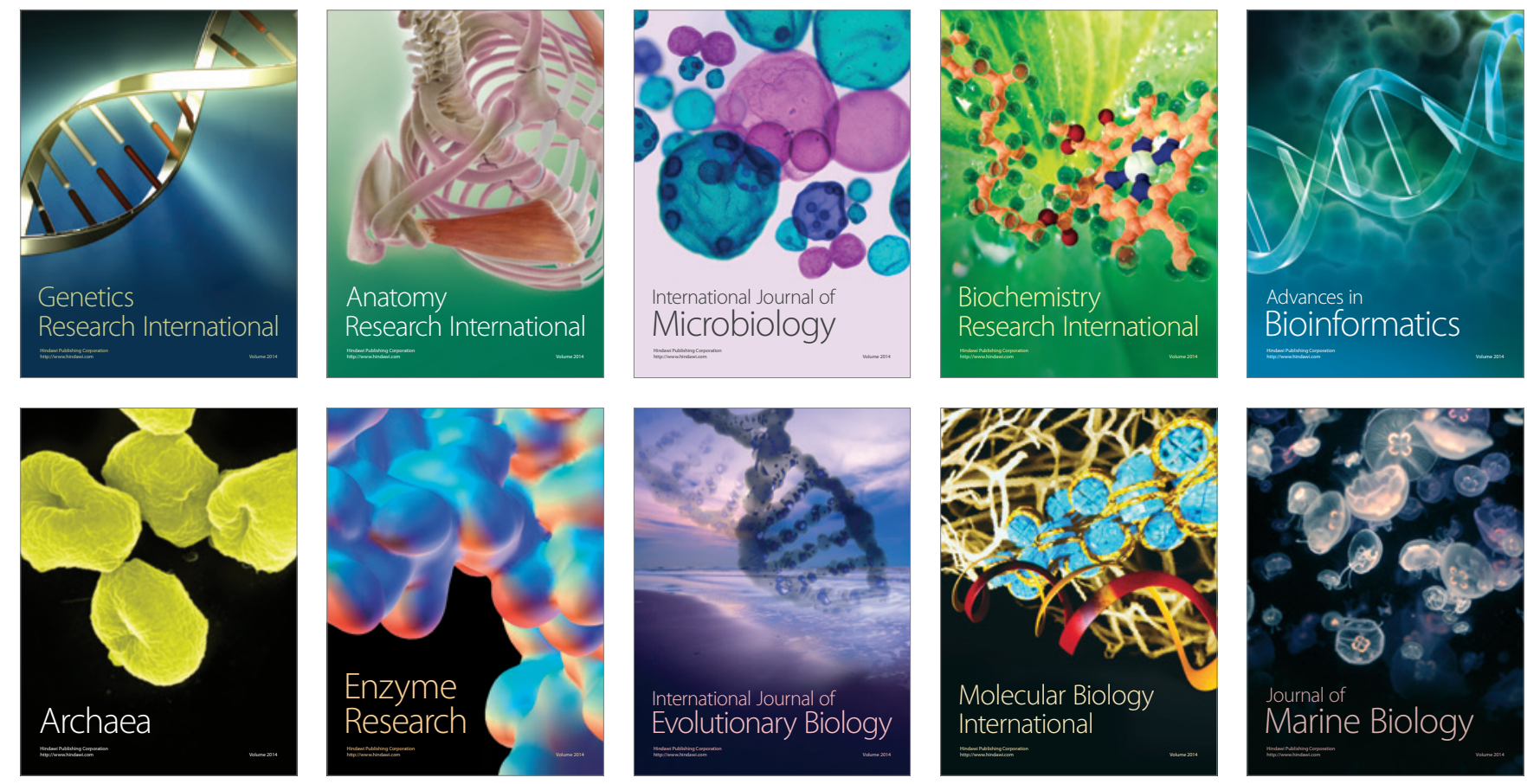